\title{
SINGLE-WALLED CARBON NANOTUBE BUCKYPAPERS AS ELECTROCATALYST SUPPORTS FOR METHANOL OXIDATION
}

\author{
J.M. Sieben ${ }^{a}$, A. Ansón-Casaos ${ }^{b}$, M.T. Martínez ${ }^{b}$, E. Morallón ${ }^{a}$ \\ a Departamento de Química Física and Instituto Universitario de Materiales, Universidad de Alicante, Ap. 99 Alicante, \\ Spain. ${ }^{\mathrm{b}}$ Instituto de Carboquímica, CSIC, Miguel Luesma 4, 50018 Zaragoza, Spain.
}

\section{Abstract}

This work studies the use of various single-walled carbon nanotube (SWCNT) buckypapers as catalyst supports for methanol electro-oxidation in acid media. Buckypapers were obtained by vacuum filtration from pristine and oxidized SWCNT suspensions in different liquid media. Pt-Ru catalysts supported on the buckypapers were prepared by multiple potentiostatic pulses using a diluted solution of $\mathrm{Pt}$ and $\mathrm{Ru}$ salts $\left(2 \mathrm{mM} \mathrm{H}_{2} \mathrm{PtCl}_{6}+2 \mathrm{mM} \mathrm{RuCl}\right)$ in acid media. The resulting materials were characterized via SEM, TEM, EDX and ICP-OES analysis. Well dispersed rounded nanoparticles between 2 and $15 \mathrm{~nm}$ were successfully electrodeposited on the SWCNT buckypapers. The ruthenium content in the bimetallic deposits was between 32 and 48 at. \%, while the specific surface areas of the catalysts were in the range of 72 to $113 \mathrm{~m}^{2} \mathrm{~g}^{-1}$. It was found that the solvent used to prepare the SWCNT buckypaper films has a strong influence on the catalyst dispersion, particle size and metal loading. Cyclic voltammetry and chronoamperometry experiments point out that the most active electrodes for methanol electro-oxidation were prepared with the buckypaper supports that were obtained from SWCNT dispersions in N-methylpyrrolidone.

Keywords: carbon nanotube buckypaper, Pt-Ru catalyst, electrodeposition, methanol oxidation

*Corresponding author: E. Morallón, Tel: +34-965909590. Fax: +34-965909820. E-mail address: morallon@ua.es 


\section{Introduction}

Single-walled carbon nanotubes (SWCNTs) are very attractive materials due to their exceptional geometry and properties at the nanoscale. SWCNTs exhibit excellent electronic conductivity and superior mechanical performance, high surface area, high chemical stability and also fast electron-transfer kinetics for electrochemical reactions. The preparation of SWCNT-based films has been up to date the most successful way to transfer SWCNT properties from the nano- to the microscale level [1], leading to formation of strong and light-weight materials [2]. As a result, SWCNT films are promising materials for flexible electronics, chemical and biological sensors, transparent electrodes in solar cells and displays, artificial actuators and nanostructured electrodes in batteries, supercapacitors and fuel cells [3].

Proton exchange membrane fuel cells (PEMFCs) are amongst the most promising alternative energy source for the near future, primarily to power electric vehicles and portable electronic devices. Nowadays, the most important goal of the researchers is to reduce the cost and to improve durability. The main strategy involves decreasing the platinum loading in fuel cell electrodes by optimization of the electrode structures and implementation of more active Pt alloy catalysts, as well as the development of highly-conductive membranes, although further work is required to optimize the combined performance and durability of catalysts and membranes in the Membrane Electrode Assembly (MEA) [4].

Carbon nanotube buckypapers (BPs) are black paper-like sheets made of interwoven mats of nanotubes. BPs are extremely promising supports for platinum-based catalysts, because catalyst nanoparticles can be located on the most accessible external surface of the buckypaper network, improving Pt utilization. Besides, the empty spaces between the bundles of nanotubes can be filled 
by Nafion ionomer which facilitates the increase in the three-phase boundary [5]. Additionally, reactant access and product removal can be enhanced by modulating the inter-tubes porosity, either through the filtration pressure or the nanotubes concentration [6].

Several methods for synthesizing Pt nanoparticles on carbon nanotubes have been proposed [7]. Among them, electrodeposition is particularly attractive because it is a simple low cost method and also the metal particles can be deposited selectively at desired locations on the three-phase boundary with enough electron, proton and reactant access. There are some works dealing with the preparation of supported platinum catalysts over nanotubes films by electrochemical techniques [5,8-11]. Zhu et al. have published a series of reports focused to evaluate the behavior of carbon nanotube buckypaper films as catalyst supports for PEMFC [5,8-10]. The authors prepared catalysts with low and ultralow platinum loadings by electrodeposition, resulting in electrodes with a relatively high metal utilization, high activity and good durability in a single fuel

cell test due to the maximization of the three-phase boundary. Ramesh et al. [11] evaluated the performance of $\mathrm{Pt} / \mathrm{BP}$ electrodes with ultralow metal loadings as the cathode catalyst layer in PEMFC. They found that this electrode configuration improves the mass transport within the catalyst layer and increases the mass activity as well as produces an efficient proton transport without additional Nafion in the catalyst layer.

This work studies the use of various BPs as Pt-Ru catalyst supports. The influence of the buckypaper preparation on the characteristics of the electrodeposited catalysts and their activity for methanol oxidation is examined by SEM, TEM, EDX and electrochemical techniques.

\section{Experimental}

SWCNTs were purchased from Carbon Solutions Inc., Riverside, CA, USA (AP-SWNT grade) and from Sigma-Aldrich (704121). SWCNTs from Carbon Solutions (CS-SWCNTs) are synthesized 
by the electric arc reactor method using Ni/Y catalyst and contain $\sim 30 \mathrm{wt} . \%$ metal residue. The average diameter and length of the CS-SWCNTs is $1.89 \mathrm{~nm}$ and $509 \mathrm{~nm}$, according to atomic force microscopy measurements [12]. Sigma-Aldrich 704121 SWCNTs are supplied by Southwest Nanotechnologies, Norman, OK, USA (SWeNT SG 76 grade). These nanotubes (SW-SWCNTs) are synthesized by a chemical vapor deposition method utilizing cobalt and molybdenum as the catalysts (CoMoCAT process). According to the provider, SW-SWCNTs have diameters of 0.7-1.1 $\mathrm{nm}$ and an average length of $800 \mathrm{~nm}$. Metal residue is less than $10 \mathrm{wt} . \%$. More than $50 \%$ of the nanotubes show $(7,6)$ chirality.

Six carbon nanotube buckypapers (BP1, BP2, BP3, BP4, BP5 and BP6) were prepared by vacuum filtration through $0.1 \mu \mathrm{m}$ Omnipore membranes (Millipore). BP1, BP2 and BP3 were made of pristine CS-SWCNTs, while BP4 and BP5 contained oxidized nanotubes (Ox-CS-SWCNTs). Oxidation of the CS-SWCNTs was performed by thermal treatment in air atmosphere in an oven at $350^{\circ} \mathrm{C}$ for $1 \mathrm{~h}$. The weight change during the process was from 70 to $64 \mathrm{mg}$ ( $8.6 \%$ weight loss). BP6 was made of pristine SW-SWCNTs.

For BP1, $30 \mathrm{mg}$ of the CS-SWCNT powder was tip sonicated (UP 400S Hielscher, 0.5 cycles, $60 \%$ amplitude) in $25 \mathrm{ml}$ of dimethyl-formamide (DMF), filtered and washed with ether. BP2 was prepared from a dispersion of the CS-SWCNT powder in aqueous $1 \%$ sodium dodecylbenzenesulfonate (SDBS). $60 \mathrm{mg}$ of SWCNTs were mixed with $25 \mathrm{ml}$ of the SDBS solution, bath sonicated for $30 \mathrm{~min}$, tip sonicated for $1 \mathrm{~h}$ and magnetically stirred at $60^{\circ} \mathrm{C}$ for $24 \mathrm{~h}$. The resulting dispersion was centrifuged at $13,000 \mathrm{rpm}(20,000 \mathrm{~g})$ for $30 \mathrm{~min}$ and the supernatant was carefully decanted and filtered. BP3 was prepared from a poly-vinylidene-fluoride (PVDF) solution in DMF containing $5 \mathrm{mg}$ of PVDF powder (Aldrich, $\mathrm{M}_{\mathrm{w}} \sim 534,000$ ) and $25 \mathrm{ml}$ of DMF. 30 mg of CS-SWCNTs were added to the PVDF/DMF solution and were twice bath sonicated for 30 min and tip sonicated for $1 \mathrm{~h}$. For BP4 and BP5, $30 \mathrm{mg}$ of Ox-CS-SWCNTs were tip sonicated in 
$25 \mathrm{ml}$ of DMF and N-methyl-pyrrolidone (NMP), respectively. For BP6, $30 \mathrm{mg}$ of SW-SWCNTs were tip sonicated in $25 \mathrm{ml}$ of NMP. Curiously, BP6 experienced radial shrinkage after filtration, during the drying of the residual NMP.

Characterization of the SWCNT powder samples was performed by visible/near infrared (Vis/NIR) absorption spectroscopy and thermogravimetric analysis (TGA). Vis/NIR spectra were measured in $2 \mathrm{ml}$ quartz cubettes utilizing a Bruker VERTEX 70 spectrometer (NIR region) and a Shimadzu UV-2401 PC spectrometer (visible region). The SWCNT powders were tip sonicated in aqueous $1 \%$ SDBS and diluted with the surfactant until adjusting the absorbance at approximately 0.4 units at $850 \mathrm{~nm}$. TGA of the SWCNT powders was carried out in a Setaram balance, model Setsys Evolution, under an argon inert flow and a heating ramp of $5{ }^{\circ} \mathrm{C} \mathrm{min}^{-1}$.

Buckypapers sheets $\left(\sim 5 \mathrm{mg} \mathrm{cm}^{-2}\right)$ were stuck onto polished glassy carbon (GC) discs of 0.07 $\mathrm{cm}^{2}$ exposed geometric area by using a Nafion solution (5 wt. \%).

Conventional three-compartment glass cells were used to run the electrochemical experiments at room temperature with a PAR 263 potentiostat/galvanostat. The counter-electrode was a platinum wire, and a reversible hydrogen electrode (RHE) served as reference electrode. All potentials mentioned in this work are referred to this electrode. An inert nitrogen atmosphere was maintained over the electrolyte during the experiments.

The bimetallic catalysts were synthesized by electrodeposition at room temperature using freshly prepared diluted solutions of $2 \mathrm{mM} \mathrm{H} \mathrm{PtCl}_{6}+2 \mathrm{mM} \mathrm{RuCl} 3$ in $0.5 \mathrm{M} \mathrm{H}_{2} \mathrm{SO}_{4}$. The electrodeposition was carried out using multiple successive potentiostatic pulses $\left(E_{1}=0.05 \mathrm{Vt} t_{1}=\right.$ $5 \mathrm{~s}, \mathrm{E}_{2}=0.5 \mathrm{Vt}_{2}=5 \mathrm{~s}$ ), applying 90 consecutive cycles. After deposition, the electrodes were thoroughly rinsed with ultrapure water and tested in sulfuric acid solution using cyclic voltammetry (CV) at a sweep rate of $50 \mathrm{mV} \mathrm{s}^{-1}$. 
The active surface area of the electrocatalysts was determined by copper underpotential deposition (Cu-UPD). Experimental details have been described elsewhere [13].

The electrode performance for methanol electro-oxidation was measured in $1 \mathrm{M} \mathrm{CH}_{3} \mathrm{OH} / 0.5 \mathrm{M}$ $\mathrm{H}_{2} \mathrm{SO}_{4}$ solution by applying a potential sweep at a scan rate of $50 \mathrm{mV} \mathrm{s}^{-1}$. Chronoamperograms were obtained applying potential pulses for $15 \mathrm{~min}$ from an initial potential of $0 \mathrm{~V}$. Current densities for methanol oxidation were normalized per milligram of Pt.

The morphology of the catalyst surface and the particle size were analyzed using TEM microscopy (JEOL JEM-2010). Bulk composition analysis was performed by an energy dispersive spectroscopy (EDX, Bruker XFlash 3001) probe attached to a SEM microscope (Hitachi S3000N).

The amount of Pt and Ru deposited on the substrates was estimated using ICP-OES analysis (Perkin Elmer 7300 DV).

\section{Results and Discussion}

\subsection{Characterization of the SWCNTs}

Important details regarding the electronic character, diameter and chirality of the SWCNTS can be extracted from Vis/NIR absorption spectra (Fig.1). CS-SWCNT spectrum shows the characteristic bands of metallic $\left(\mathrm{M}_{11}\right.$ band) and semiconducting $\left(\mathrm{S}_{22}\right.$ band) SWCNTs at approximately $600-800 \mathrm{~nm}$ and $900-1200 \mathrm{~nm}$, respectively. Both spectral bands correspond to electronic transitions of multiple SWCNT chirality types. The Ox-SWCNT spectrum is almost identical to that for pristine CS-SWCNTs, except for an increase in the relative intensity of the SWCNT bands with respect to the background signal. Therefore, no substantial changes in the chirality and diameter distribution occurred during the oxidative thermal treatment. The increase in

the relative intensity of the SWCNT features is associated to a purity improvement in terms of SWCNT mass per total carbon mass. 
The Vis/NIR spectrum of SW-SWCNTs is clearly different from that of CS-SWCNTs. The relative intensity of the SWCNT characteristic features is strong, indicating a remarkably pure SWCNT material. Instead of broad $S_{22}$ and $M_{11}$ spectral bands, SW-SWCNTs show some prominent peaks that correspond to particular chiralities. The peak at around $1150 \mathrm{~nm}$ corresponds to the $(7,6)$ chiral type, which is the majority one in the sample, in agreement with the provider specifications.

Surface oxygen of the SWCNT powder materials was studied by TGA in an inert gas flow (Fig. 2). Most of the surface functional groups evolve during the heating at temperatures between 150 ${ }^{\circ} \mathrm{C}$ and $800-900{ }^{\circ} \mathrm{C}$, mainly as $\mathrm{CO}_{2}$ and $\mathrm{CO}$. Moisture is detected at temperatures around $100^{\circ} \mathrm{C}$. Weight losses above $\sim 900^{\circ} \mathrm{C}$ can be assigned to residual oxygen groups and to the evolution of amorphous carbon in the form of carbon gas radicals. It is interesting to note that even the pristine CS-SWCNT powder contains a certain amount of oxygen surface groups, which evolve at around $640{ }^{\circ} \mathrm{C}$, causing a weight loss of $\sim 1.5-2$ wt. $\%$. As it is expected, greater weight losses were detected for the Ox-CS-SWCNT powder, since many surface oxygen groups were generated during air oxidation. The evolution of surface oxygen from Ox-CS-SWCNT powders mostly occurred at around $500-600^{\circ} \mathrm{C}$, causing a weight loss of $\sim 8 \mathrm{wt}$. \%. Those surface groups evolving at $500-600{ }^{\circ} \mathrm{C}$ are anhydride or lactone groups [14]. Other high stability groups (carbonyl-quinone), which evolve at temperatures higher than $600^{\circ} \mathrm{C}$, coexist on the Ox-CS-SWCNT surfaces.

Surprisingly, TGA of pristine SW-SWCNTs shows a continuous weight loss from $100^{\circ} \mathrm{C}$ to 800 ${ }^{\circ} \mathrm{C}$ that reaches $\sim 7 \%$ of the total weight. Therefore, pristine SW-SWCNTs contain much more surface oxygen than pristine CS-SWCNTs. This fact is most probably associated to the synthetic origin of each SWCNT material. CS-SWCNTs were produced by the arc discharge method and are highly graphitized, while SW-SWCNTs were produced by chemical vapor deposition at a relatively low temperature and contain a substantial amount of structural defects. Additionally, the thermal 
stability of SW-SWCNT surface oxygen is clearly different from that of Ox-CS-SWCNTs. While nearly no weight loss was registered for Ox-CS-SWCNTs at temperatures below $500{ }^{\circ} \mathrm{C}$ (due to the previous heat treatment in air), a continuous weight loss reaching $\sim 5 \%$ was detected for the SW-SWCNTs. This weight loss below $500{ }^{\circ} \mathrm{C}$ is probably associated to surface carboxylic acids [15].

\subsection{Characterization of carbon nanotubes buckypapers}

Fig. 3 shows the voltammetric response for the buckypaper-modified GC electrodes and for a polished GC electrode in acid media. CVs show a current increase for all the BP electrodes and reveal the rectangular shape characteristic of a double layer profile with non-faradaic processes. Besides, BP4, BP5 and BP6 exhibits redox peaks that are characteristic of the presence of oxygenated surface groups $[16,17]$, which influence the electrochemical interfacial state of the carbon surface and its double-layer properties.

The specific surface area $\left(S_{w}\right)$ and the electroactive surface area (S) of all materials can be estimated assuming a value of $10 \mu \mathrm{F} \mathrm{cm}{ }^{-2}$ for the specific capacitance of CNTs [18]. The values of specific surface area $\left(S_{w}\right)$, the electroactive surface area $(S)$ and the specific capacitance obtained from the voltammograms for all buckypapers are listed in Table 1. Close examination of the potentiodynamic profiles and data of this table also indicated that the specific surface area $\left(S_{w}\right)$ may follow the order $\mathrm{BP} 6 \approx \mathrm{BP} 5>\mathrm{BP} 4>\mathrm{BP} 1>\mathrm{BP} 3>\mathrm{BP} 2$. As it can be observed, the anionic surfactant SDBS has a more pronounced effect on the active surface area and the specific capacitance than that observed with DMF, NMP and PVDF as SWCNTs dispersant.

The differences in the magnitude of $\mathrm{C}$ and $\mathrm{S}_{\mathrm{w}}$ among the BPs can be explained assuming that the dispersants block to a greater or lesser extent the electroactive area of the nanotube network by the formation of hydrophobic domains that hinder the access of ions of the electrolyte to the 
electrode surface. Besides, the organic compounds fill up the pores in the nanotube network and substantially reduce the electroactive surface area, i.e. electrolyte solution enters more (or less) into the structure of the BPs. On the other hand, the presence of oxygenated functional groups contributes to the electrochemical properties of BP4, BP5 and BP6 increasing these values of surface area and capacitance. Amongst all buckypaper samples, BP6 displays the highest gravimetric capacitance $\left(37 \mathrm{~F} \mathrm{~g}^{-1}\right)$. This value is lower than that informed for pristine single walled carbon nanotubes $\left(52 \mathrm{~F} \mathrm{~g}^{-1}\right)$ [19], but very similar to those reported for electrodes prepared by drop casting $\left(37 \mathrm{~F} \mathrm{~g}^{-1}\right)$, air brushing $\left(35 \mathrm{~F} \mathrm{~g}^{-1}\right)$, electrospraying $\left(42 \mathrm{~F} \mathrm{~g}^{-1}\right)$ and SWCNTs mixed with cellulose filter paper $\left(36 \mathrm{~F} \mathrm{~g}^{-1}\right)[20]$.

SEM micrographies of the six BP-modified GC electrodes are shown in Fig. 4. At first inspection, some differences between the films can be observed. For the BP1 electrode a disordered tangle of nanotube bundles is shown at the surface. For the BP2 electrode a ramified structure is observed at the surface, although most of the surface seems to be covered by the anionic surfactant. In addition, the carbon nanotube network is not clearly visible at the surface of the BP3 electrode, showing that most of the bundles are surrounded by a film of polyvinilidenfluoride but with high surface roughness and porosity. On the other hand, BP4 and BP5 exhibit a porous and rough surface due to the presence of entangled mats of SWCNTs, whereas BP6 exhibits a more open surface structure and the nanotube bundles are thickly interwoven forming ropes.

\subsection{Physicochemical characterization of the catalysts}

Pt-Ru bimetallic particles with controlled composition could be prepared by adjusting the ratio of platinum and ruthenium salts in the solution. The atomic composition of Pt-Ru catalysts was determined by the EDX technique (see Fig. S1) and ICP-OES analysis. Table 2 shows the 
parameters of the Pt-Ru catalyst electrodeposited on carbon nanotube buckypapers. The Ru content $\left(\mathrm{X}_{\mathrm{Ru}}\right.$, at. \%) determined by the two methods is almost identical in the three first samples (BP1-PR, BP2-PR and BP3-PR) in agreement with the ratio of the metal concentrations in the electrodeposition solutions. This result can be rationalized considering that $\mathrm{Ru}$ is codeposited with Pt on the BP at a lower overpotential than when it is deposited as a single metal, favored kinetically by the platinum nuclei formed over the carbon support [21]. However, the ruthenium content in the three last samples (BP4-PR, BP5-PR and BP6-PR) is lower than that measured in the other ones. This result could indicate that the oxygenated surface groups modify the way that platinum and ruthenium particles are deposited over the substrate. According to a previous work [22], the interface is altered when the substrate is oxidized and this modification can change the real electrodeposition potential of the electrode, modifying the conditions for platinum and ruthenium electrodeposition. Besides, the kinetics of the Pt nucleation process may be accelerated by the presence of the oxygenated groups, limiting Ru nucleation. Alternatively, the electronic interaction between the $\mathrm{Pt}$ particles and the oxygenated surface groups may influence the nucleation of the Ru atoms.

From Table 1 it can also be seen that the specific surface area of the catalyst depends on the nature of the buckypaper, and it seems to be proportional to the specific surface area $\left(S_{w}\right)$ of the substrate. The largest value of electroactive surface area of the catalysts (ESA) is obtained with BP6 as support, followed by BP5 and BP4 respectively. This result may be related to the decrease in Pt-Ru particle size, along with a more uniform dispersion of the bimetallic nanoparticles over the support since platinum and ruthenium precursor solution is more accessible to the nanotube network of BP6 than of the other carbon nanotubes buckypapers. These results demonstrate that the electrochemical procedure is able to make bimetallic catalysts of high specific surface area. 
Fig. 5 shows transmission electron microscopy images of the buckypaper supported catalysts. The electrodeposition method leads to the formation of hemispherical and irregular particles appearing regularly distributed over the support surface with sizes in the range of 2 to $15 \mathrm{~nm}$ (Table 2). Whereas, the rounded particles of about $15 \mathrm{~nm}$ comprise agglomerates of small particles of about 2-3 nm diameter interconnected via grain boundaries. Nanoparticles gradually grow during the electrodeposition procedure and eventually overlap producing the coalescence of individual particles. Besides, the surface diffusion of individual nanoparticles and their lateral sticking may result in particle agglomeration. In addition, some degree of agglomeration can be expected when $\mathrm{H}_{2} \mathrm{PtCl}_{6}$ is used as precursor because $\mathrm{Pt}(\mathrm{IV})$ is not prone to forming $\pi$-complexes with fragments of the support surface [23].

TEM image of BP1-PR shows the presence of nanoparticles with diameters of 2 to $3.5 \mathrm{~nm}$ and agglomerates of 12 to $15 \mathrm{~nm}$. The electrode BP3-PR, do not exhibit appreciable differences in the structure of the bimetallic deposit (figure not shown), although better particle dispersion and a larger quantity of particles of 2-3.5 nm in diameter is observed at the surface of BP1 support, whereas bigger nanoparticles $(7 \mathrm{~nm})$ together with a higher degree of agglomeration and a wide particle distribution are observed on the surface of BP2-PR catalyst (Fig. 5b).

Conversely, a better particle distribution is observed in the other three catalysts (BP4-PR, BP5PR and BP6-PR). The TEM images of the catalysts reveal the presence of a large amount of nanoparticles which exhibit uniform size and almost rounded shape appearing regularly distributed over the buckypaper surfaces with sizes between 2.0 and $3.5 \mathrm{~nm}$. However, BP4-PR and BP5-PR images also show the existence of some agglomerates of around 8 and $15 \mathrm{~nm}$ formed by nanoparticles of sizes ranging from 2 to $3 \mathrm{~nm}$ (Fig. 5c). Interestingly, sample BP6-PR does not exhibit such amount of agglomeration compared to the other catalysts. 
These results indicate that apparently particle size and distribution and agglomeration degree of the bimetallic electrodeposited catalysts are considerably influenced by the presence of the dispersant used to prepare the nanotube films and also by the content and type of surface oxygen groups.

\subsection{Methanol electro-oxidation}

Fig. 6 shows the cyclic voltammograms of the catalysts recorded at $50 \mathrm{mV} \mathrm{s}^{-1}$ in $1 \mathrm{M}$ $\mathrm{CH}_{3} \mathrm{OH} / 0.5 \mathrm{H}_{2} \mathrm{SO}_{4}$ at room temperature during the fifth cycle. For all the electrodes the onset potential of the methanol oxidation seems to take place near $0.4 \mathrm{~V}$. The beginning of methanol oxidation at this potential is associated with the formation of $\mathrm{OH}_{\text {ads }}$ species on $\mathrm{Ru}$ atoms originating in the water dissociation that occurs at potentials more negative than that on $\mathrm{Pt}$ atoms, through the so called bifunctional mechanism. The forward scan peak of methanol electro-oxidation for the first four catalysts appears at a potential of $0.85 \mathrm{~V}$. Whereas, the peak potential for the other two electrodes (BP5-PR and BP6-PR) is shifted by about $0.1 \mathrm{~V}$ in the positive direction as a result of their lower Ru content. In the reverse scan, an anodic peak is observed for all the catalysts at ca.

$0.75 \mathrm{~V}$. Methanol electro-oxidation takes place through multiple steps [24] involving several intermediates (and mainly $\mathrm{CO}_{a d s}[25,26]$ ) that poisons the catalyst surface. Hence, the anodic peak observed in the backward scan is attributed to the oxidative removal of these carbonaceous species adsorbed on the bimetallic particles [27].

The voltammograms also point out that BP6-PR has the greatest activity for methanol oxidation and the intensity of the anodic current during the forward scan is decreased by the order of BP5PR, BP4-PR, BP1-PR, BP3-PR and BP2-PR. In fact, the activity per mass unit of BP6-PR catalyst is 1.4, 1.9, 2.5, 3.3 and 4 times higher than when BP5-PR, BP4-PR, BP1-PR, BP3-PR and BP2PR electrodes are used to oxidize methanol. The superior catalytic activity of BP6-PR could be 
explained in terms of their smaller average particle size, better distribution of the bimetallic particles over the carbon nanotube film. The values obtained are similar in order of magnitude and somewhat higher than those obtained as similar conditions by other authors $[28,29]$.

In addition, the electrode effectiveness on methanol conversion to $\mathrm{CO}_{2}$ can be evaluated in terms of the ratio of the forward peak current density $\left(\mathrm{j}_{\mathrm{pf}}\right)$ to reverse peak current density $\left(\mathrm{j}_{\mathrm{pb}}\right)$. In other words this relationship can be used to infer the $\mathrm{CO}$ tolerance of the catalyst. The $\mathrm{j}_{\mathrm{p} f} \mathrm{j}_{\mathrm{pb}}$ value is almost identical for all electrodes (between 2.3 and 3), suggesting that all materials exhibit comparable $\mathrm{CO}$ tolerance to poisoning.

Current transient measurements at constant potentials were carried out for $900 \mathrm{~s}$ (Fig. 7), showing that the different electrodes present the same behavior as that observed in the voltammetric curves between $0.6 \mathrm{~V}$ and $0.7 \mathrm{~V}$. At potentials below $0.6 \mathrm{~V}$ BP6-PR prevails as the best catalyst for the electro-oxidation of the alcohol, followed by BP5-PR. However, the catalytic activity of BP4-PR is surpassed by catalyst BP1-PR at potentials lower than $0.6 \mathrm{~V}$. This behavior may be associated with the existence of a compromise between the available Pt sites (surface area) for producing the dissociative adsorption of the alcohol and the amount of $\mathrm{OH}_{\text {ads }}$ species on $\mathrm{Ru}$ atoms (ruthenium content) capable of promoting the complete oxidation of the carbonaceous residues. The results are summarized in Table 3. Chronoamperometric curves in Fig. 7 shows a high initial current density for methanol oxidation, which rapidly decays to a much lower value. This current decay is observed in the literature for bimetallic Pt-Ru catalysts at diverse temperatures and methanol concentrations. This deactivation is caused by blocking access of the active sites due to the formation of poisoning species [30]. Chemisorption of methanol gives rise to the adsorption of $\mathrm{CHO}$ and $\mathrm{CO}$ intermediaries with the former detected at low potentials.

Through the electrochemical experiments of methanol oxidation on the different electrodes, it was found that the buckypaper prepared with SW-SWCNTs dispersed in NMP (BP6) is able to 
achieve a higher performance with lower metal loading than some Pt-Ru catalysts prepared by electrodeposition over other carbon materials [22,31,32].

The behavior of the Pt-Ru/BPs electrodes was compared with some data available in the literature. For instance, the catalytic performance of BP6-PR for methanol oxidation is higher than those reported by Jiang et al. [33] for a $\mathrm{Pt}_{0.5} \mathrm{Ru}_{0.5} / \mathrm{N}$-doped CNT catalyst and by Sun et al. [34] for a catalyst $\mathrm{Pt}_{0.5} \mathrm{Ru}_{0.5} / \mathrm{CeO}_{2} / \mathrm{CNT}$, but with lower $\mathrm{Pt}$ loading. These promising results open the possibility of tailoring highly active electrodes for fuel cells applications. Most of Pt-based catalyst can be situated on the outer part of the SWCNTs framework close to the polymeric membrane, which allows to achieve high platinum utilization efficiency and to reduce transport limitations of protons and reactants [5].

\section{Conclusions}

This work shows that carbon nanotube buckypapers are promising support materials for the preparation of highly active Pt-based catalysts by electrochemical deposition.

The electrochemical behavior showed that the bimetallic catalyst supported on the different SWCNT buckypapers have excellent catalytic activity toward methanol oxidation at room temperature.

It was found that the dispersant used to prepare the carbon nanotube buckypaper has a considerable influence on the electroactive surface area of the single-walled carbon nanotube network, which in turn influences catalyst loading, particle size and catalyst distribution over the support. The influence of the solvent/dispersant seems to be even greater than that of SWCNT purity and the presence of surface oxygen functional groups. 
Acknowledgment. J.M.S. thanks Ministerio de Educación (SB2010-132). Financial support from MINECO and FEDER (MAT2010-15273, TEC 2010-15736 and PRI-PIBAR-2011-1 projects) and GV (ACOMP/2012/133 project) is acknowledged.

\section{References}

[1] A. Ansón-Casaos, J.M. González-Domínguez, E. Terrado, M.T. Martínez, Carbon 48 (2010) 1480-1488.

[2] M. Endo, H. Muramatsu, T. Hayashi, Y.A. Kim, M. Terrones, M.S. Dresselhaus, Nature 433 (2005) 476-476.

[3] L. Hu, D.S. Hecht, G. Grüner, Chem. Rev. 110 (2010) 5790-5844.

[4] J.S. Spendelow, D.C. Papageorgopoulos, Fuel Cells 11 (2011) 775-786.

[5] W. Zhu, J.P. Zheng, R. Liang, B. Wang, C. Zhang, G. Au, E.J. Plichta, Electrochem. Commun. $12(2010)$ 1654-1657.

[6] A. Deneuve, K. Wang, I. Janowska, K. Chizari, D. Edouard, O. Ersen, M.-J. Ledoux, C. PhamHuu, Appl. Catal. A 400 (2011) 230-237.

[7] K. Lee, J. Zhang, H. Wang, D.P. Wilkinson, J. Appl. Electrochem. 36 (2006) 507-522.

[8] W. Zhu, D. Ku, J.P. Zheng, Z. Liang, B. Wang, C. Zhang, S. Walsh, G. Au, E.J. Plichta, Electrochim. Acta 55 (2010) 2555-2560.

[9] W. Zhu, J.P. Zheng, Z. Liang, B. Wang, C. Zhang, S. Walsh, G. Au, E.J. Plichta, J. Electrochem. Soc. 156 (2009) B1099-B1105.

[10] W. Zhu, J.P. Zheng, Z. Liang, B. Wang, C. Zhang, S. Walsh, G. Au, E.J. Plichta, ECS Transactions (The Electrochemical Society) 16 (2008) 1615-1626.

[11] P. Ramesh, M.E. Itkis, J.M. Tang, R.C. Haddon, J. Phys. Chem. C 112 (2008) 9089-9094.

[12] A.J. Blanch, C.E. Lenehan, J.S. Quinton, Carbon 49 (2011) 5213-5228. 
[13] J.M. Sieben, M.M.E. Duarte, C.E. Mayer, J. Appl. Electrochem. 38(2008) 483-490.

[14] A. Anson-Casaos, M. Gonzalez, J.M. Gonzalez-Dominguez, M.T. Martinez, Langmuir 27 (2011) 7192-7198.

[15] J.L. Figueiredo, M.F.R. Pereira, Catal. Today 150 (2010) 2-7.

[16] J. Maruyama, I. Abe, Electrochim. Acta, 46 (2001) 3381-3386.

[17] M.J. Bleda-Martinez, D. Lozano-Castello, E. Morallon, D. Cazorla-Amoros, A. Linares-Solano, Carbon 44 (2006) 2642-2651.

[18] S. Shiraishi, H. Kurihara, K. Okabe, D. Hulicova, A. Oya, Electrochem. Commun. 4 (2002) 593-598.

[19] T. Inoue, S. Mori, S. Kawasaki, Jpn. J. Appl. Phys. 50 (2011) 01AF07.

[20] M.H. Ervin, B.S. Miller, B. Hanrahan, B. Mailly, T. Palacios, Electrochim. Acta 65 (2012) 3743.

[21] A.N. Gavrilov, O.A. Petrii, A.A. Mukovnin, N.V. Smirnova, T.V. Levchenko, G.A. Tsirlina, Electrochim Acta 52 (2007) 2775-2784.

[22] J.M. Sieben, M.M.E. Duarte, C.E. Mayer, ChemCatChem 2 (2010) 182-189.

[23] E.R. Savinova, N.P. Lebedeva, P.A. Simonov, G.N. Kryukova, Russ. J. Electrochem. 36 (2000) 952-959.

[24] J.M. Sieben, Mater. Chem. Phys. 128 (2011) 243-249.

[25] T. Seiler, E.R. Savinova, K.A. Friedrich, U. Stimming, Electrochim. Acta 49 (2004) 3927-3936.

[26] Z. Jusys, R.J. Behm, J. Phys. Chem. B 105 (2001) 10874-10883.

[27] H. Okamoto, W. Kon, Y. Mukouyama, J. Phys. Chem. B 109 (2005) 15659-15666.

[28] J. Guo, G. Sun, S. Shiguo, S. Yan, W. Yang, J. Qi, Y. Yan, Q. Xin, J. Power Sources, 168 (2007) 299-306.

[29] D.J. Guo, L. Zhao, X. Qiu, L. Chen, W. Zhu, J. Power Sources, 177 (2008) 334-338. 
[30] H.A. Gasteiger, N. Markovic, P.N. Ross Jr, E. Cairns, J. Electrochem. Soc. 141 (1994) 17951803.

[31] J.M. Sieben, M.M.E. Duarte, C.E. Mayer, J. Alloys Compd. 509 (2011) 4002-4009.

[32] J.M. Sieben, M.M.E. Duarte, Int. J. Hydrogen Energy 37(2012) 9941-9947.

[33] S. Jiang, L. Zhu, Y. Ma, X. Wang, J. Liu, J. Zhu, Y. Fan, Z. Zou, Z. Hu, J. Power Sources 195 (2010) 7578-7582.

[34] Z. Sun, X. Wang, Z. Liu, H. Zhang, P. Yu, L. Mao, Langmuir 26 (2010) 12383-12389. 


\section{Figure Captions}

Figure 1: Visible/NIR spectra of CS-SWCNTs (a), Ox-CS-SWCNTs (b) and SW-SWCNTs (c) dispersed in aqueous $1 \%$ SDBS (without centrifugation).

Figure 2: TGA $\left(\operatorname{Ar}, 5^{\circ} \mathrm{C} \mathrm{min}^{-1}\right)$ of the CS-SWCNT (a), Ox-CS-SWCNT (b) and SW-SWCNT (c) powder materials.

Figure 3: Steady cyclic voltammograms of the different carbon nanotube buckypapers in $0.5 \mathrm{M}$ $\mathrm{H}_{2} \mathrm{SO}_{4} \cdot \mathrm{v}=50 \mathrm{mV} \mathrm{s}^{-1}$.

Figure 4: SEM images of the SWCNT buckypapers: BP1 (a), BP2 (b), BP3 (c), BP4 (d), BP5 (e) and BP6 (f).

Figure 5: TEM images of all Pt-Ru/BPs catalysts: BP1-PR (a), BP2-PR (b), BP4-PR (c) and BP6PR (d).

Figure 6: Steady cyclic voltammograms for Pt-Ru/BPs catalysts in $1 \mathrm{M} \mathrm{CH}_{3} \mathrm{OH} / 0.5 \mathrm{M} \mathrm{H}_{2} \mathrm{SO}_{4}$, at room temperature. Electrodes: BP1-PR, BP2-PR and BP3-PR (a); BP4-PR, BP5-PR and BP6-PR (b). $v=50 \mathrm{mV} \mathrm{s}^{-1}$.

Figure 7: Chronoamperometry curves at different potentials (vs. RHE) for Pt-Ru/BPs electrodes in $1 \mathrm{M} \mathrm{CH}_{3} \mathrm{OH} / 0.5 \mathrm{M} \mathrm{H}_{2} \mathrm{SO}_{4}$, at room temperature from an initial potential of $0 \mathrm{~V}$. Electrodes: BP1-PR (a), BP2-PR (b), BP3-PR (c), BP4-PR (d), BP5-PR (e) and BP6-PR (f). 
Table 1. Buckypaper descriptions and electrochemical parameters extracted from CV measurements at $50 \mathrm{mV} \mathrm{s}^{-1}$ in $0.5 \mathrm{M} \mathrm{H}_{2} \mathrm{SO}_{4}$ electrolyte solution.

\begin{tabular}{clccc}
\hline Buckypaper ID & \multicolumn{1}{c}{ Description } & $\begin{array}{c}\mathrm{C} / \\
\mathrm{F} \mathrm{g}^{-1}\end{array}$ & $\begin{array}{c}{ }^{1} \mathrm{~S} / \\
\mathrm{cm}^{2}\end{array}$ & $\begin{array}{c}{ }^{2} \mathrm{~S}_{\mathrm{w}} / \\
\mathrm{m}^{2} \mathrm{~g}^{-1}\end{array}$ \\
\hline BP1 & CS-SWCNTs, DMF & 15 & 468 & 149 \\
BP2 & CS-SWCNTs, aq SDBS & 9 & 179 & 88 \\
BP3 & CS-SWCNTs, PVDF/DMF & 11 & 399 & 110 \\
BP4 & Ox-CS-SWCNTs, DMF & 25 & 614 & 247 \\
BP5 & Ox-CS-SWCNTs, NMP & 36 & 1019 & 357 \\
BP6 & SW-SWCNTs, NMP & 37 & 1899 & 365 \\
\hline
\end{tabular}

${ }^{1}$ Electroactive surface area. ${ }^{2}$ Specific surface area. 
Table 2. Characterization parameters of Pt-Ru catalysts supported on BPs.

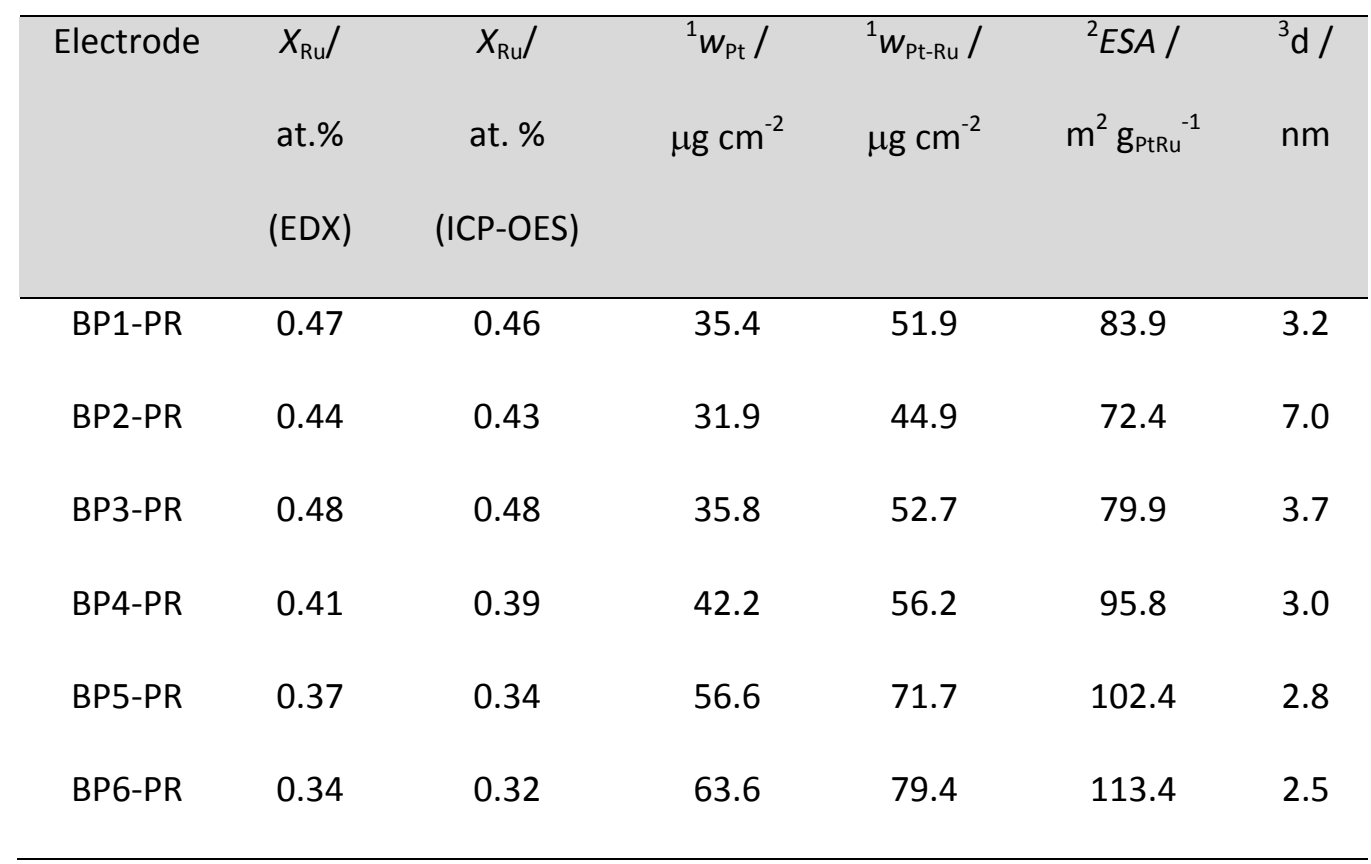

${ }^{1}$ : catalyst mass determined by ICP-OES.

${ }^{2}$ ESA: electroactive surface area determined from CU-UPD and ICP-OES analysis. ${ }^{3}$ Mean particle size from TEM. 
Table 3. Steady state catalytic activities of methanol oxidation on electrodeposited bimetallic PtRu/BPs. Data from chronoamperometric experiments.

\begin{tabular}{lcccc}
\hline Electrode & \multicolumn{4}{c}{$j / \mathrm{mA} \mathrm{mg}^{-1}$} \\
\cline { 2 - 5 } & $0.4 \mathrm{~V}$ & $0.5 \mathrm{~V}$ & $0.6 \mathrm{~V}$ & $0.7 \mathrm{~V}$ \\
\hline BP1-PR & 2.7 & 20.0 & 80.7 & 168.3 \\
BP2-PR & 0.8 & 5.2 & 26.9 & 106.8 \\
BP3-PR & 1.8 & 13.1 & 58.0 & 122.9 \\
BP4-PR & 2.3 & 14.6 & 83.7 & 190.6 \\
BP5-PR & 3.3 & 23.3 & 96.6 & 219.0 \\
BP6-PR & 4.2 & 31.2 & 134.5 & 294.0 \\
\hline
\end{tabular}




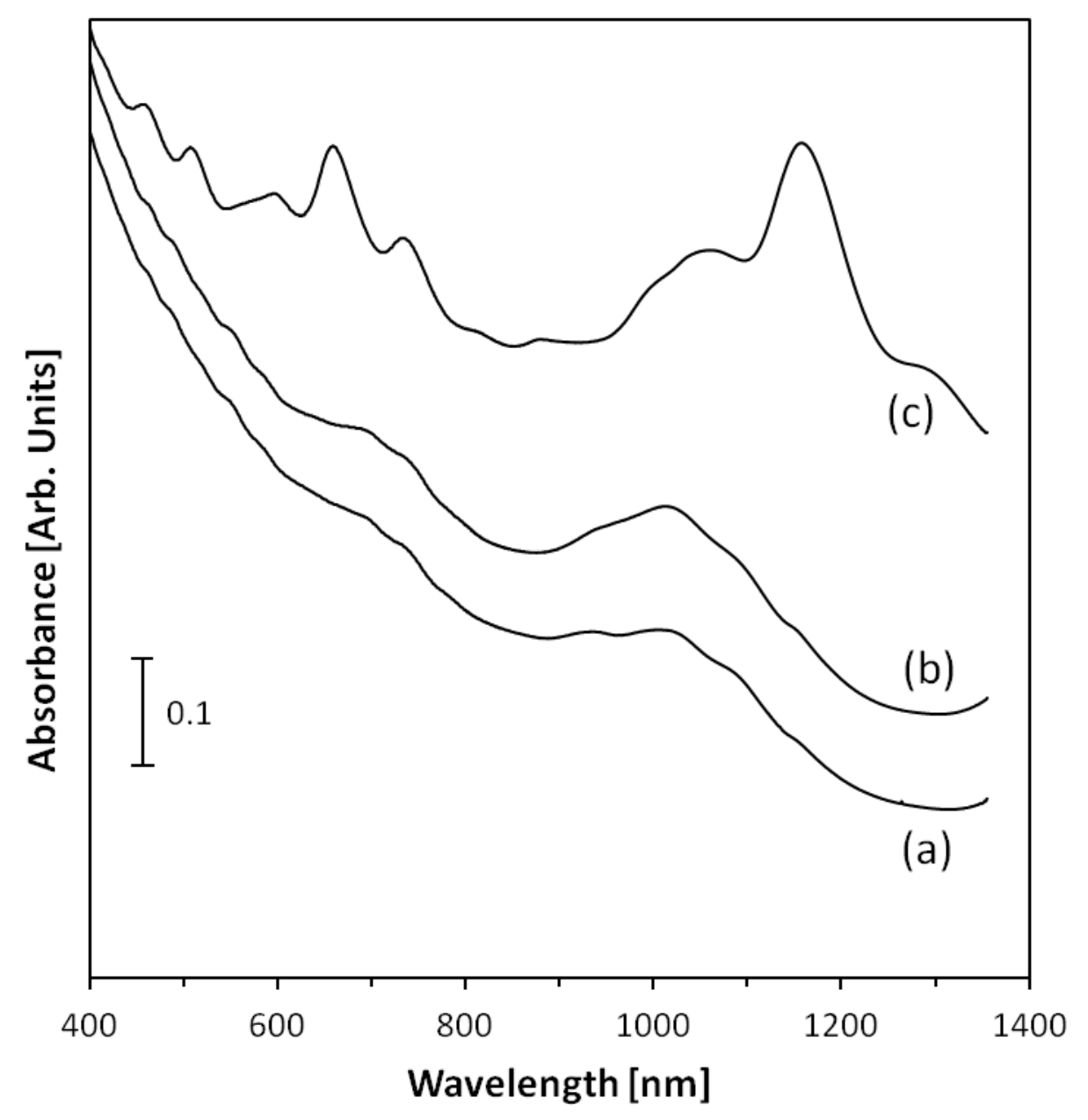

Figure 1. 


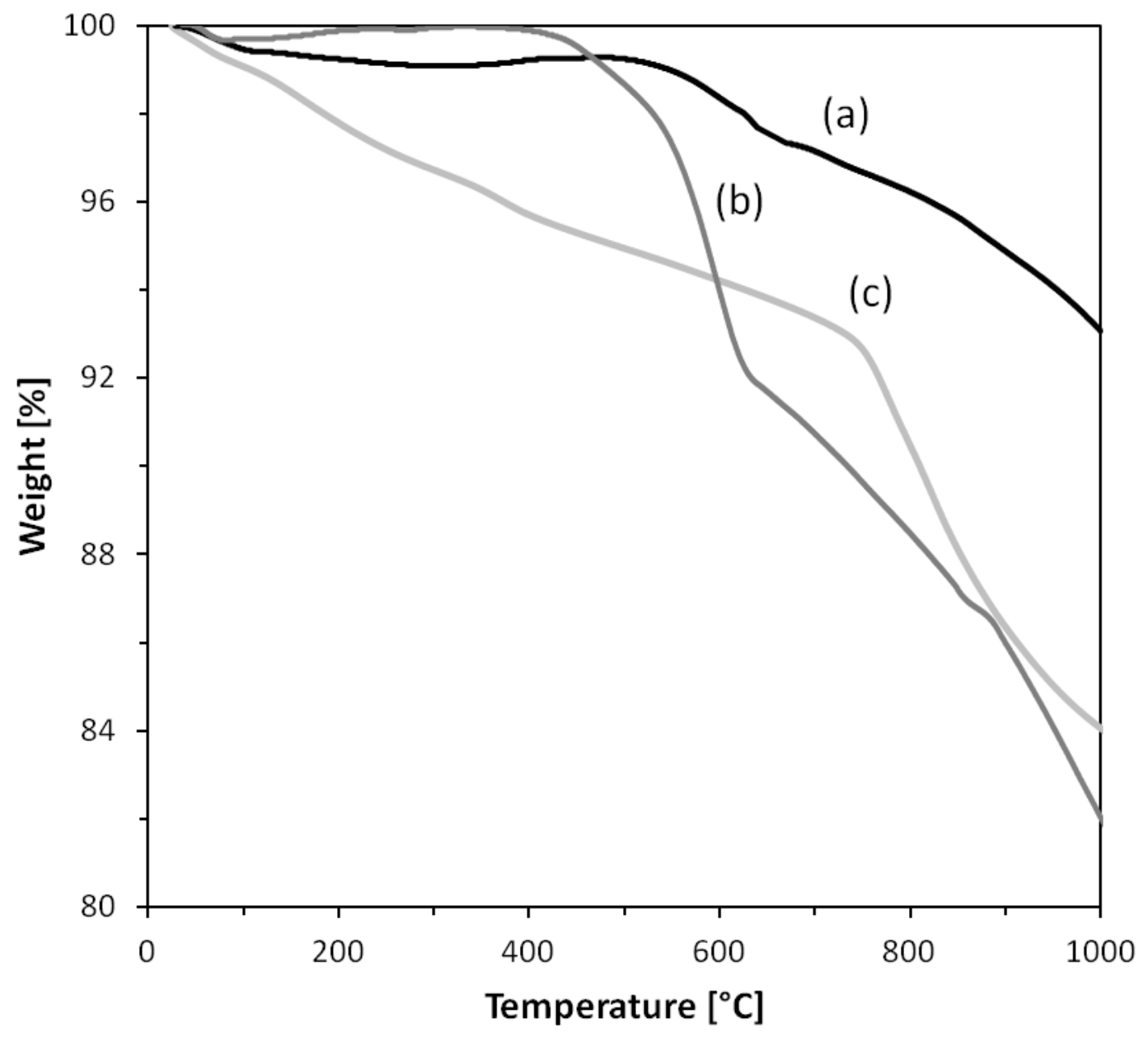

Figure 2. 


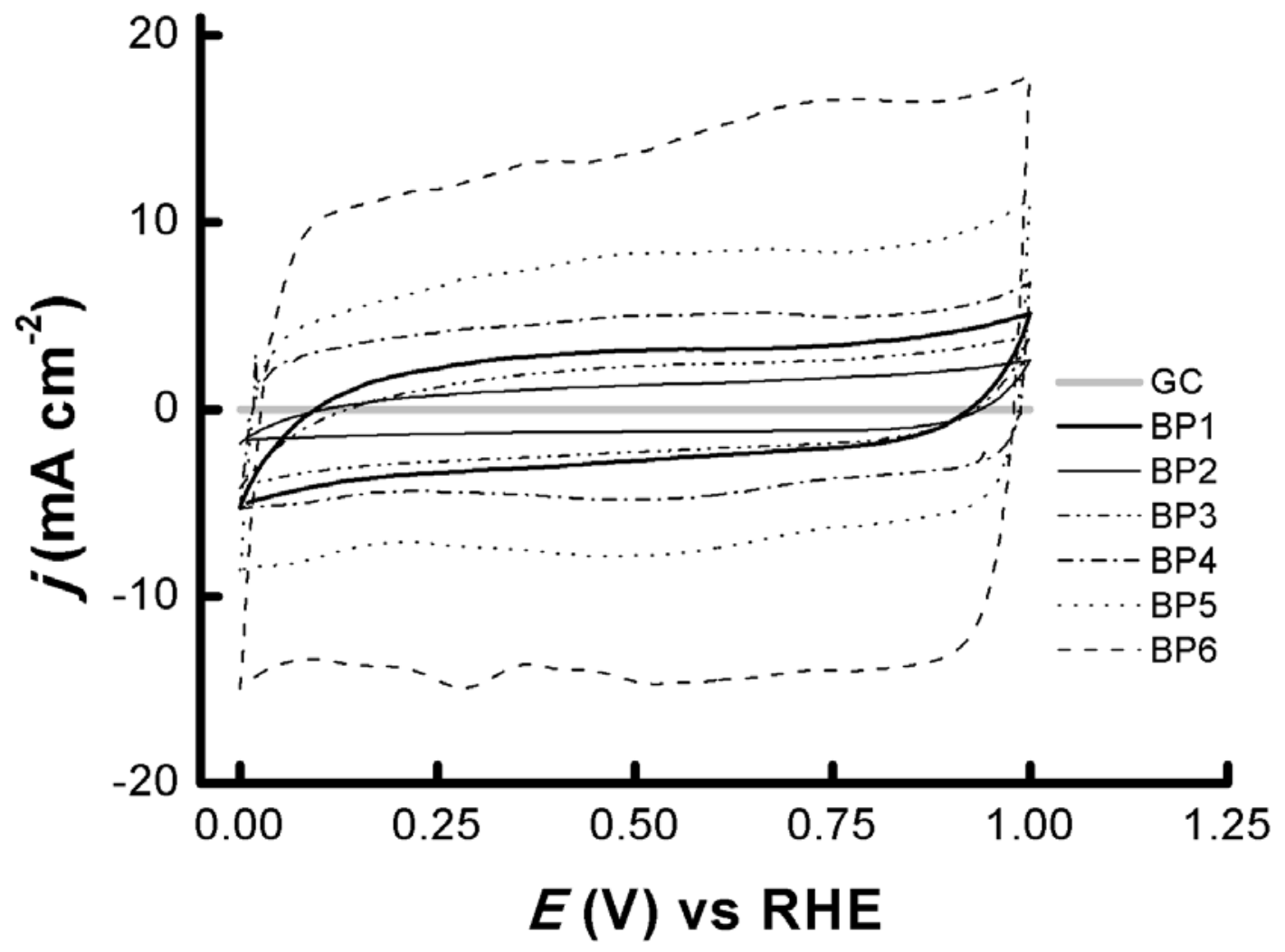

Figure 3. 

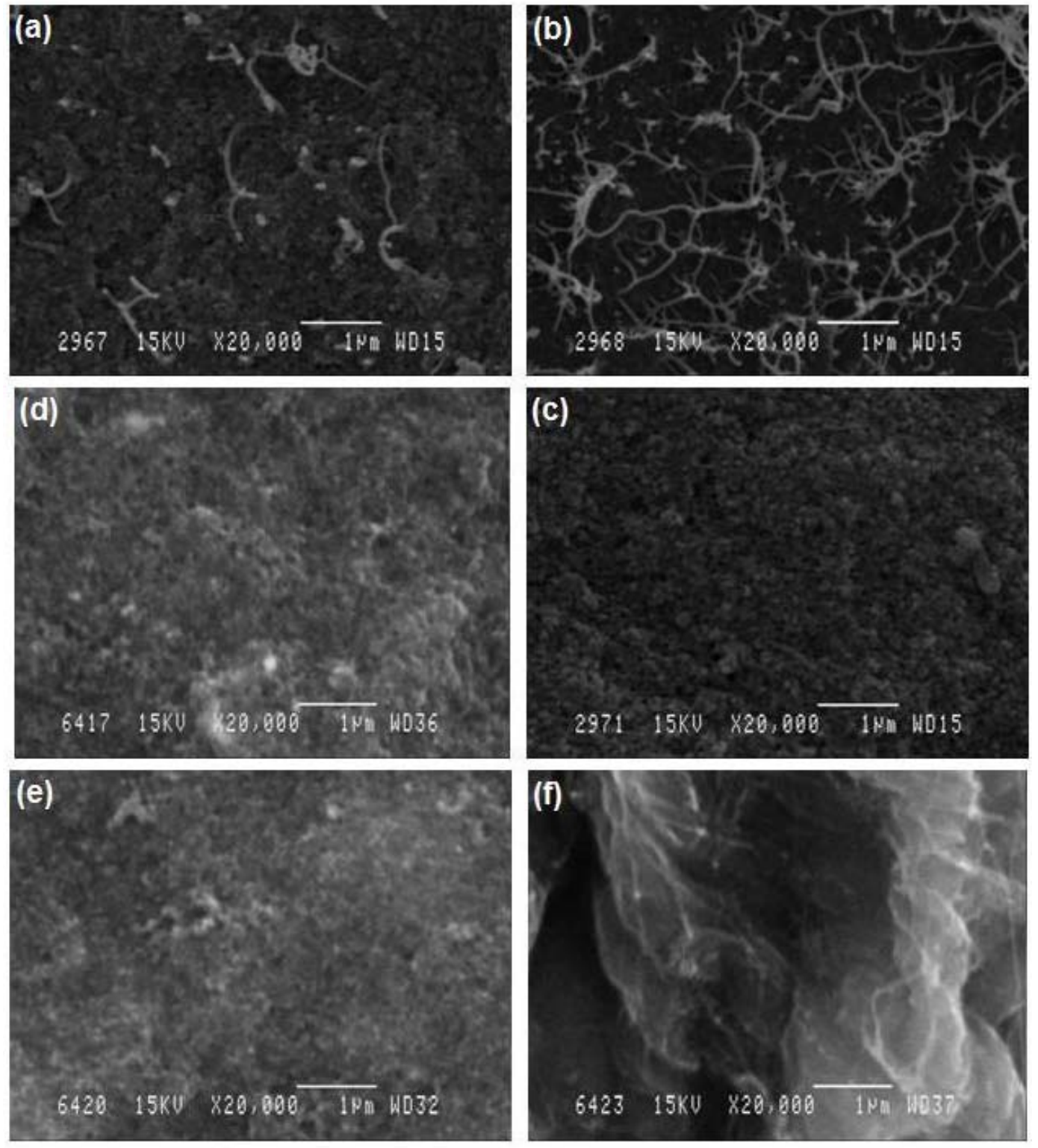

Figure 4. 

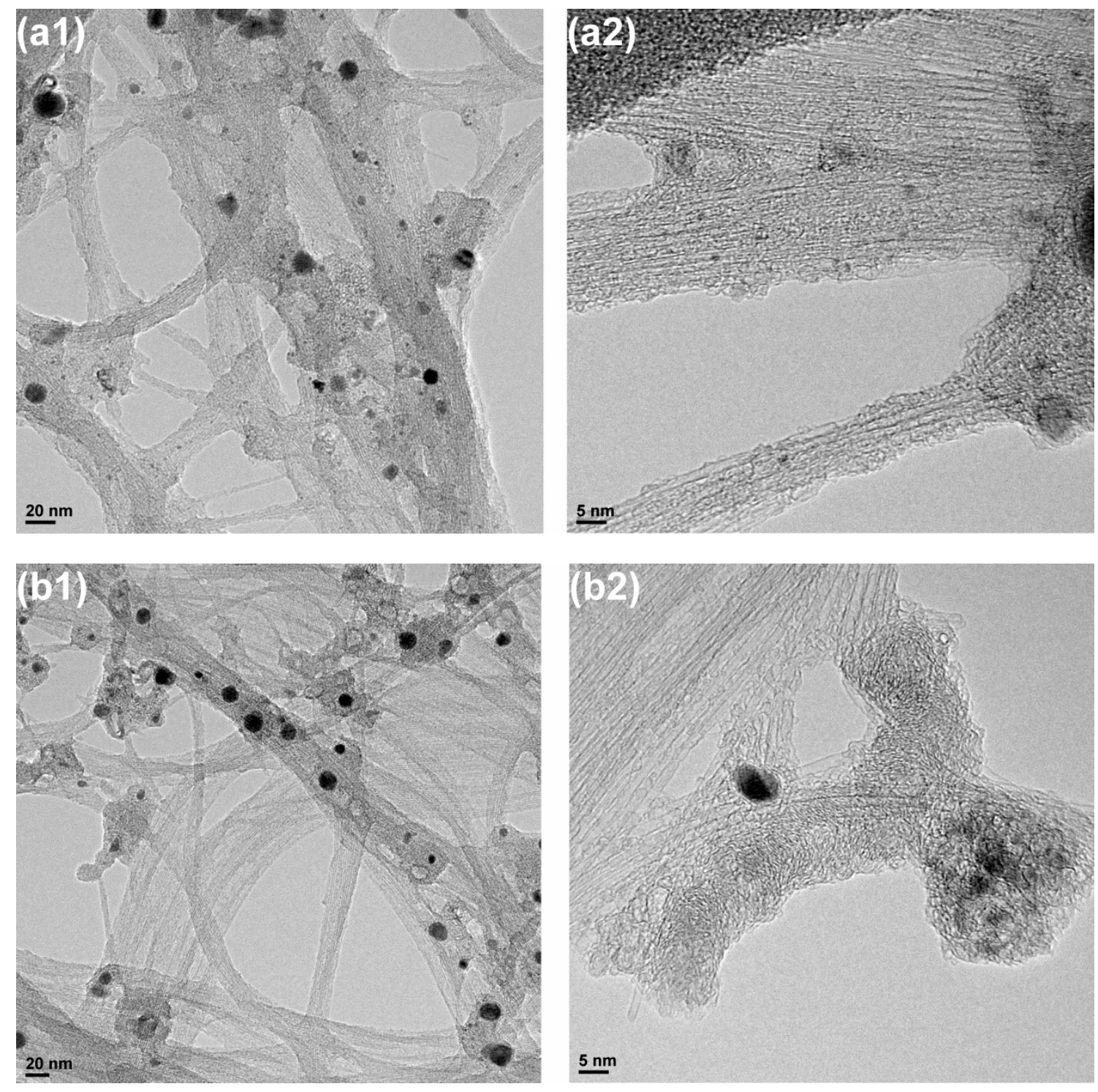

Figure 5. 

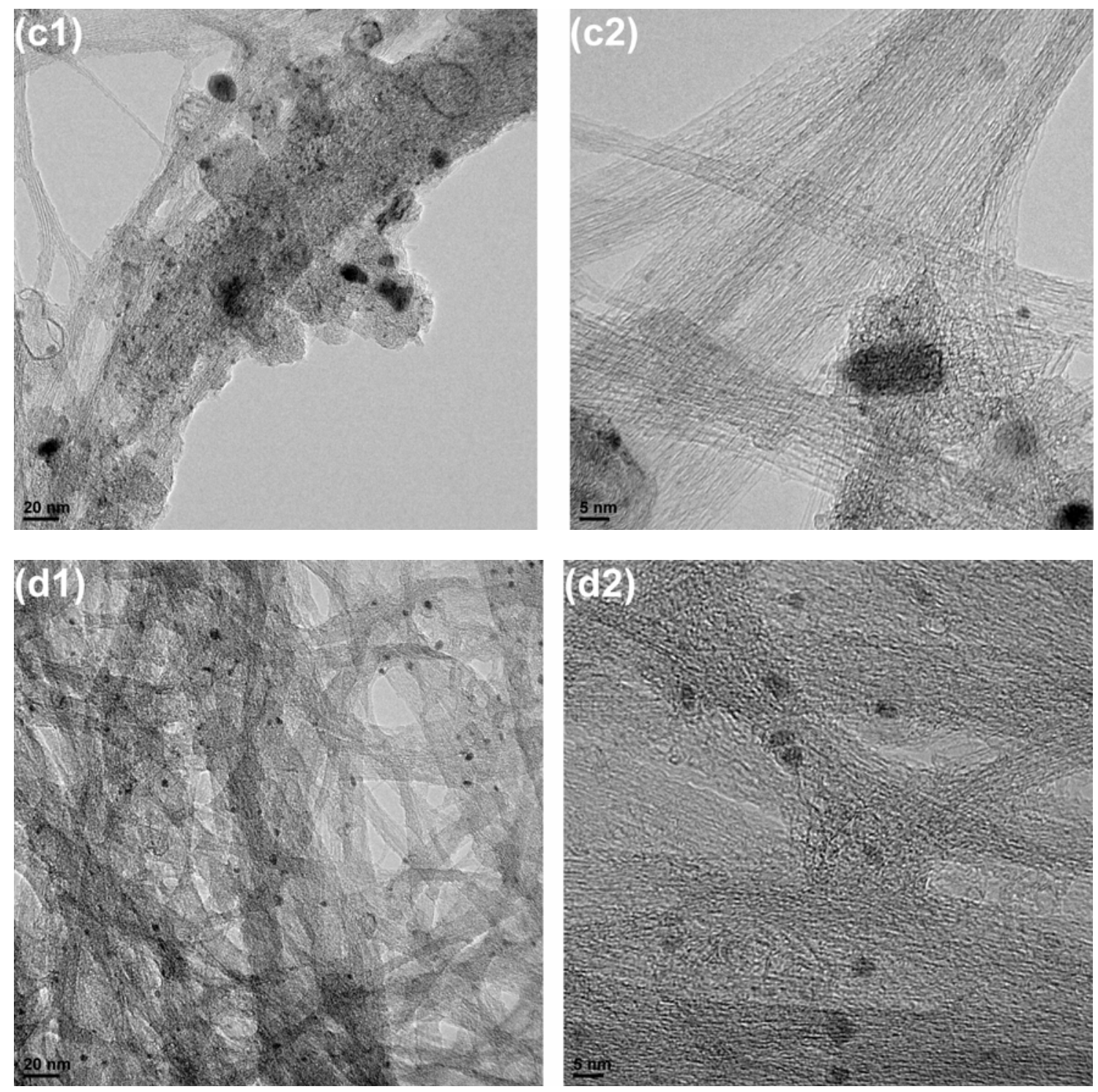

Figure 5. 


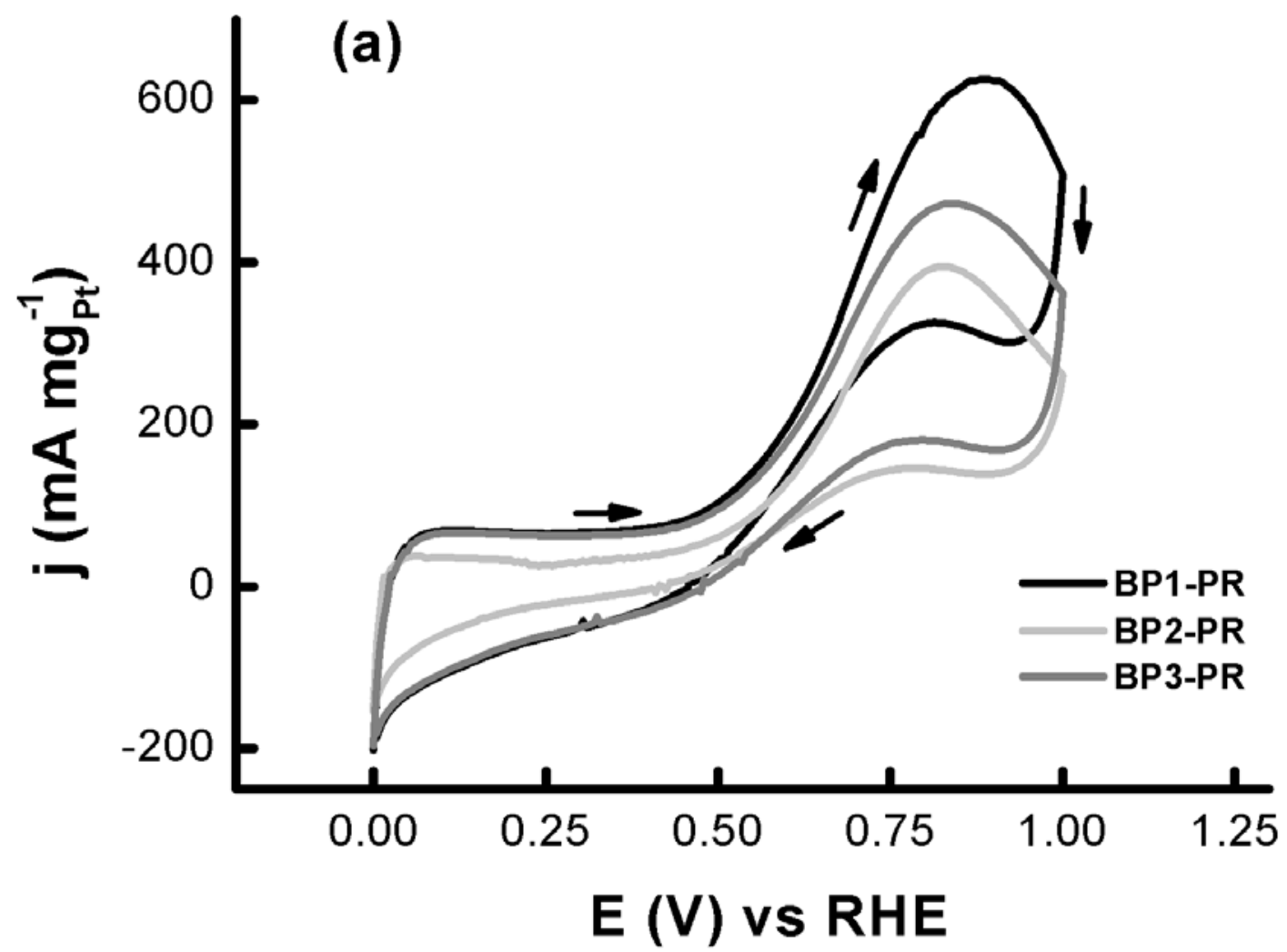

Figure 6. 


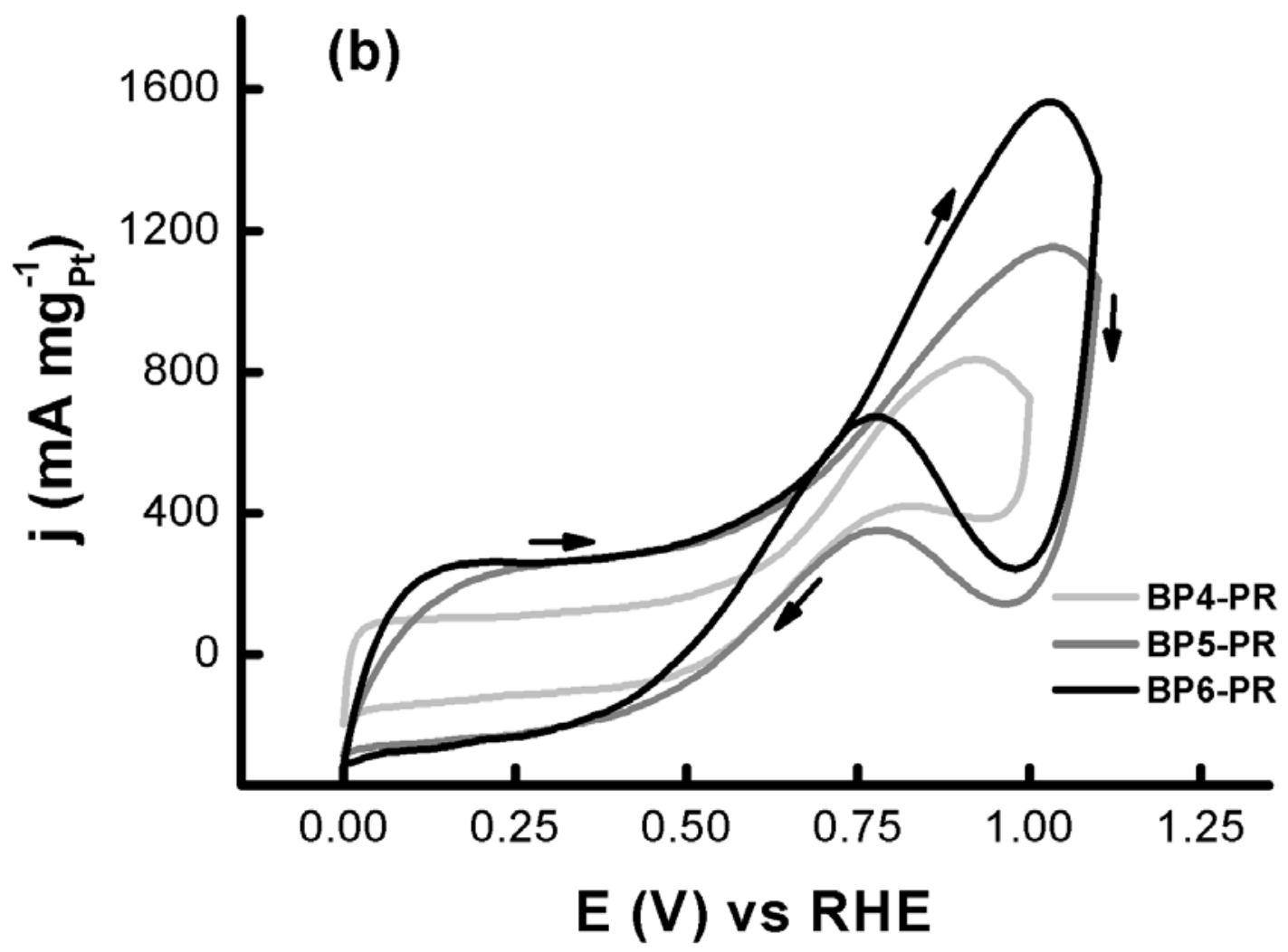

Figure 6. 

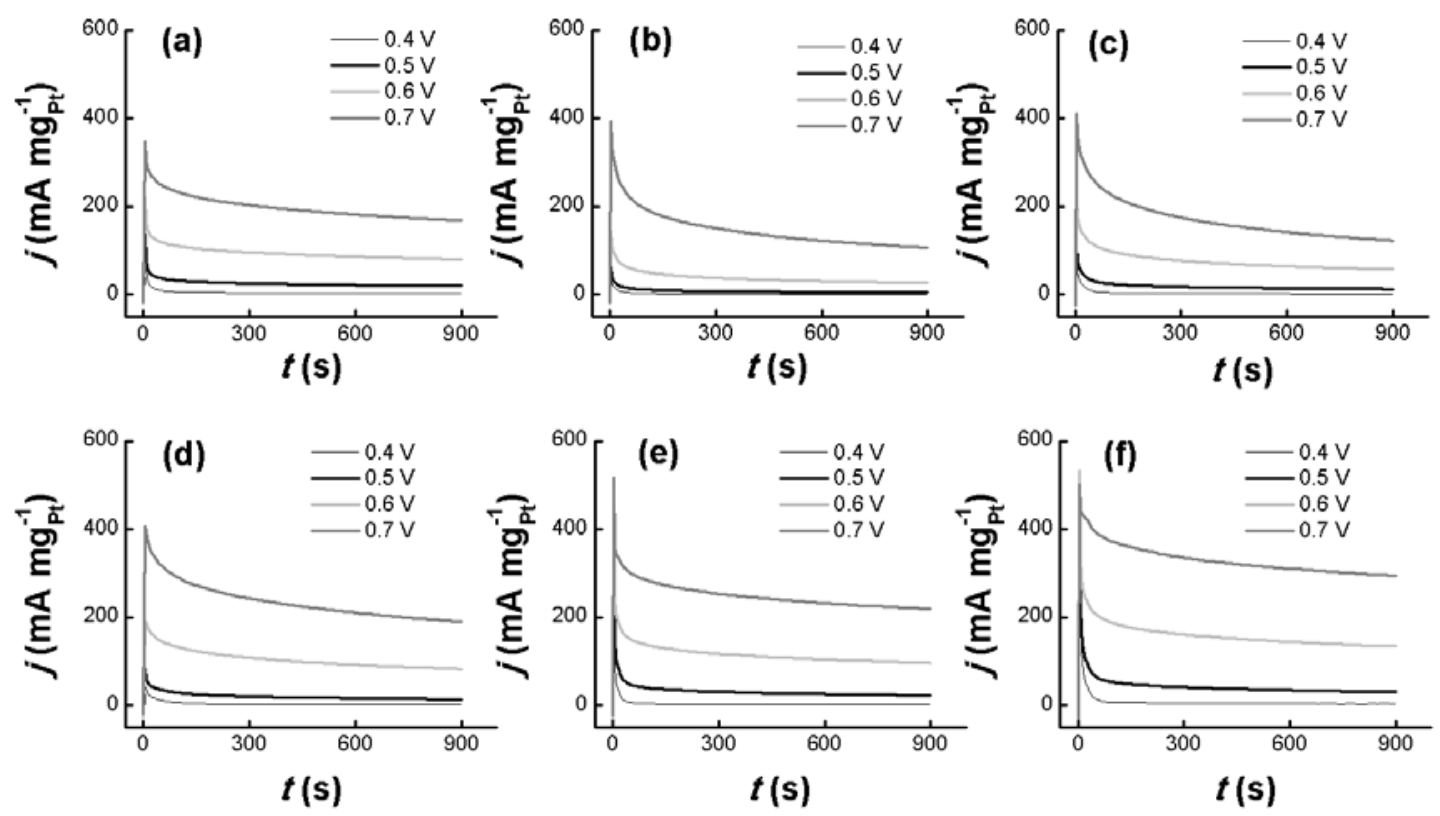

Figure 7. 

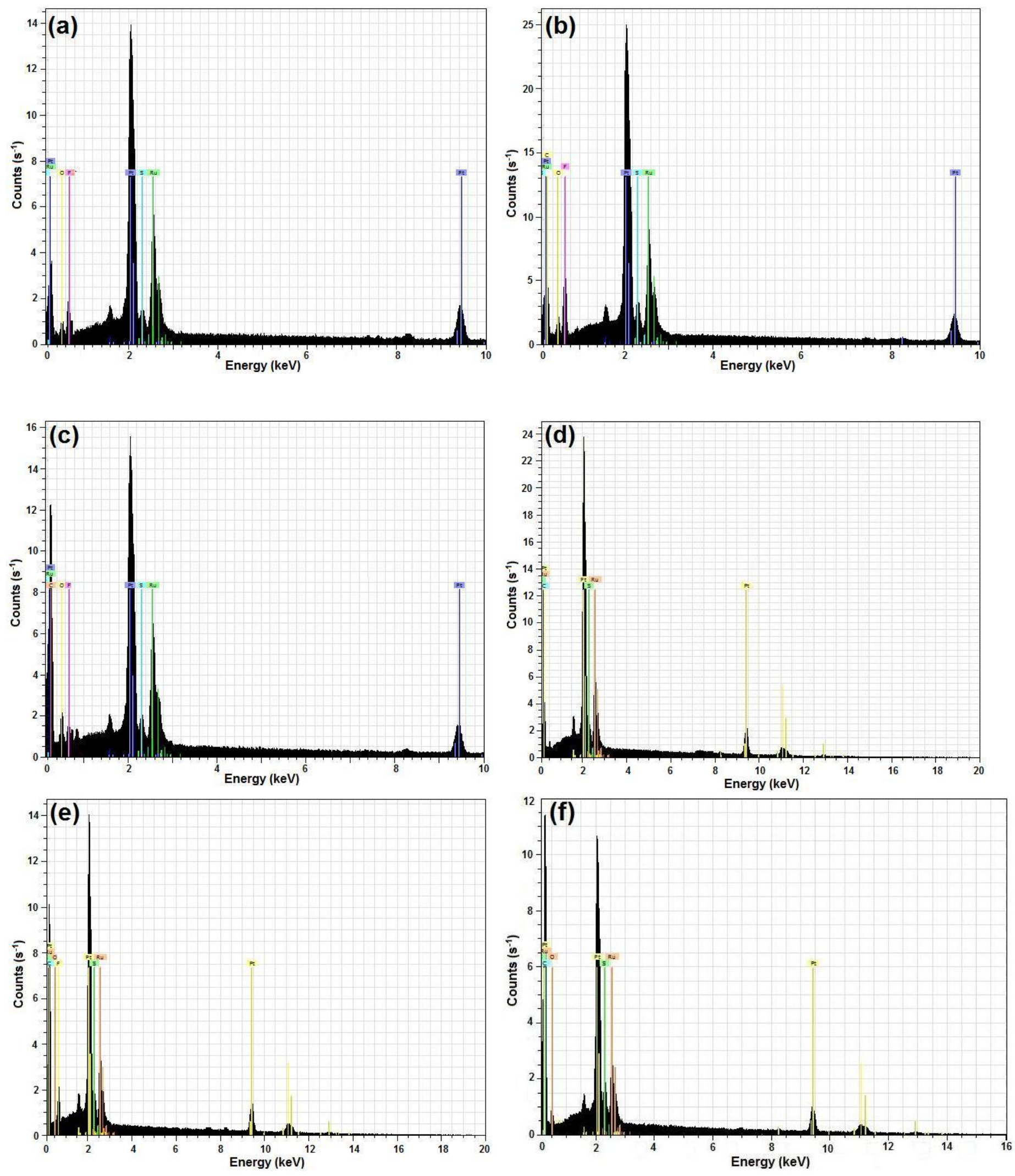
Fig. S1. EDX analysis of the different Pt-Ru/BPs electrodes: BP1-PR (a), BP2-PR (b), BP3-PR (c), BP4-PR (d), BP5-PR (e) and BP6-PR (f). 